\title{
Study of $\mathrm{Fe}_{3} \mathrm{O}_{4} / \mathrm{PS}$ System in Degrading BPA in Aqueous Solution
}

\author{
Tie-Hong Song, ${ }^{a}$ Yan-Jiao Gao, ${ }^{\circledR * b}$ Su-Yan Pang, ${ }^{c}$ Rui-Hua Hu ${ }^{c}$ and Han-Bo $\mathrm{Li}^{c}$ \\ ${ }^{a}$ Urban Construction College, Changchun University of Architecture and Civil Engineering, \\ 130118 Changchun, China \\ ${ }^{b}$ College of Civil Engineering and Architecture, Liaoning University of Technology, \\ 121001 Jinzhou, China \\ ${ }^{c}$ Key Laboratory of Songliao Aquatic Environment, Ministry of Education, Jilin Jianzhu University, \\ 130118 Changchun, China
}

\begin{abstract}
The degradation of bisphenol $\mathrm{A}$ (BPA) by $\mathrm{Fe}_{3} \mathrm{O}_{4} /$ persulfate system was investigated in aqueous solution. The influences of the initial concentrations of $\mathrm{Fe}_{3} \mathrm{O}_{4}$, persulfate (PS) and $\mathrm{BPA}, \mathrm{pH}$ value, and initial reaction temperature on BPA removal were studied. The radical species was investigated by adding excessive dose of scavenger (methanol $(\mathrm{MeOH})$ and tert-butanol (TBA)) into $\mathrm{Fe}_{3} \mathrm{O}_{4} / \mathrm{PS}$ system for the purpose of radical scavenging. The degradation products of BPA were detected by gas chromatography-mass spectrometry (GC-MS). The recyclability of $\mathrm{Fe}_{3} \mathrm{O}_{4}$ was also evaluated. The BPA removal rate of $80.7 \%$ was achieved under the following conditions: $[\mathrm{BPA}]_{0}=1 \mathrm{mg} \mathrm{L}^{-1}$, $[\mathrm{PS}]_{0}=0.2 \mathrm{mM},\left[\mathrm{Fe}_{3} \mathrm{O}_{4}\right]_{0}=0.1 \mathrm{~g} \mathrm{~L}^{-1}, \mathrm{~T}_{0}=20 \pm 1{ }^{\circ} \mathrm{C}, \mathrm{pH}_{0}=6.8 \pm 0.2$. The results confirmed that the main free radicals in the reaction process were sulfate radicals, followed by hydroxyl radicals. Some intermediate products of BPA degradation, such as phenols, benzoquinones and benzoic acid were identified by GC-MS.
\end{abstract}

Keywords: sulfate radicals, $\mathrm{Fe}_{3} \mathrm{O}_{4}$, bisphenol A, hydroxyl radicals, advanced oxidation processes

\section{Introduction}

Bisphenol A (2,2-bis(4-hydroxyphenyl)propane, BPA), a white solid, has been widely used as a ubiquitous intermediate in manufacturing polycarbonate plastics, epoxy resins and polysulfone. ${ }^{1,2}$ Therefore, BPA is present in many daily supplies, such as toys, bottles, food and beverage packaging, water supply pipes, and the polymers used in dental treatment. ${ }^{3,4} \mathrm{BPA}$ is a well-known and studied endocrine disrupting compound (EDC), which can mimic hormones and cause reproductive damage, cancer and other adverse effects on the human body and the ecological environment. ${ }^{5,6}$ Previous studies ${ }^{7,8}$ have shown that BPA can interfere with the endocrine system of humans and animals even at concentrations below $1 \mu \mathrm{g} \mathrm{m}^{-3}$. Due to the discharge of domestic sewage and industrial wastewater, as well as the infiltration of landfill leachate, BPA has frequently been found in surface water and groundwater., ${ }^{9,10}$ The study showed that the BPA concentration in some water

*e-mail: tmgyj@lnut.edu.cn environments can be as high as $100 \mu \mathrm{g} \mathrm{L}^{-1} \cdot{ }^{10}$ At present, the concentration of BPA in water environment and its harm to aquatic organisms have attracted the attention of researchers who are working on the research of refractory organics removal methods.

Since BPA is a refractory pollutant with two benzene rings, conventional biological processes in wastewater treatment plants are not efficient for complete removal of BPA. ${ }^{11}$ There are several alternative approaches that have been used to deal with the BPA over the years, such as adsorption, ${ }^{12,13}$ chlorination with sodium hypochlorite,,${ }^{14}$ and the advanced oxidation processes (AOPs). The adsorption is restricted owing to the low hydrophobicity $\left(\log \mathrm{K}_{\mathrm{ow}}\right)$ of BPA that limits the adsorption efficiency, ${ }^{15}$ and the chlorinated metabolites formed during chlorination with sodium hypochlorite cause some side effects. ${ }^{16}$ In contrast, AOPs are popular due to their ability to decompose refractory organics into biodegradable and benign products by powerful free radicals such as hydroxyl radicals $(\bullet \mathrm{OH})$ or sulfate radicals $\left(\mathrm{SO}_{4}{ }^{-}\right) .{ }^{17}$ In AOPs, ozone $\left(\mathrm{O}_{3}\right),{ }^{18}$ hydrogen peroxide $\left(\mathrm{H}_{2} \mathrm{O}_{2}\right)$, peroxymonosulfate (PMS), and persulfate 
(PS) are commonly used oxidants, which can generate free radicals after being activated by certain ways. ${ }^{11}$ For instance, in the $\mathrm{UV} / \mathrm{O}_{3}, \mathrm{UV} / \mathrm{H}_{2} \mathrm{O}_{2}$, and $\mathrm{Fe} / \mathrm{H}_{2} \mathrm{O}_{2}$ processes, $\mathrm{O}_{3}$ and $\mathrm{H}_{2} \mathrm{O}_{2}$ can produce $\cdot \mathrm{OH}$ due to $\mathrm{UV}$ or iron activation; in the UV/PS, $\mathrm{Fe}^{0} / \mathrm{PS}, \mathrm{Fe}^{\mathrm{II}} / \mathrm{PS}$, and $\mathrm{Fe}_{3} \mathrm{O}_{4} / \mathrm{PS}$ processes, $\mathrm{PS}$ can generate $\mathrm{SO}_{4}{ }^{-}$also due to $\mathrm{UV}$ or iron activation. ${ }^{11,18}$ Although $\mathrm{SO}_{4}{ }^{--}$and $\bullet \mathrm{OH}$ have close oxidizing potentials (for $\mathrm{SO}_{4}^{-{ }^{-}}, \mathrm{E}_{0}=2.6-3.1 \mathrm{~V}$; for $\bullet \mathrm{OH}, \mathrm{E}_{0}=1.8-2.7 \mathrm{~V}$ ), the half-life of $\mathrm{SO}_{4}^{-{ }^{-}}$is longer than that of $\bullet \mathrm{OH}$, and the oxidant PS is more stable than $\mathrm{O}_{3}$ and $\mathrm{H}_{2} \mathrm{O}_{2}$. On the one hand, iron is a common material with benign property, which makes it as an activator to show economic and environmental advantages. On the other hand, from the standpoint of stability, ease of storage, and generation of sulfate radicals, PS is considered to be more suitable as an oxidant in AOPs. Therefore, the use of iron to activate PS to generate free radicals in degradation of refractory organics has become one of the research hotspots in AOPs. The mechanisms by which various forms of iron activate PS are attributed to the redox reactions between $\mathrm{Fe}^{\mathrm{II}}$ and PS. Based on the existence form of iron, iron-based activator can be classified into homogeneous (such as $\mathrm{Fe}^{\amalg}$ ) and heterogeneous (such as $\mathrm{Fe}^{0}$ and $\left.\mathrm{Fe}_{3} \mathrm{O}_{4}\right) \cdot{ }^{19} \mathrm{As}$ a homogeneous activator, $\mathrm{Fe}^{\mathrm{II}}$ is completely dissolved in the solution, which easily causes excessive $\mathrm{Fe}^{\mathrm{II}}$, thereby trapping the generated free radicals and reducing the degradation efficiency of organic matter. ${ }^{20,21}$ On the contrary, as heterogeneous activates, $\mathrm{Fe}^{0}$ and $\mathrm{Fe}_{3} \mathrm{O}_{4}$ can release $\mathrm{Fe}^{\mathrm{II}}$ into the water solution at a certain rate to avoid the extinction of free radicals caused by excessive $\mathrm{Fe}^{\mathrm{II}}$. $\mathrm{Fe}_{3} \mathrm{O}_{4}$ is a preferred activator with mixed valence oxide containing $\mathrm{Fe}^{\mathrm{II}}$ and $\mathrm{Fe}^{\mathrm{III}}$, and it is able to constantly produce $\mathrm{Fe}^{\mathrm{II}}$ to react with PS and generate free radicals. In addition, $\mathrm{Fe}_{3} \mathrm{O}_{4}$ is the main component of magnetite in nature, so it is easy to obtain. Compared with $\mathrm{Fe}^{\mathrm{II}}$ and $\mathrm{Fe}^{0}$, it is easy to recover $\mathrm{Fe}_{3} \mathrm{O}_{4}$ from wastewater based on its sub-magnetism. $\mathrm{Fe}_{3} \mathrm{O}_{4}$ can also reduce the cost of large volumes of waste effluent treatment and will not result in secondary pollution. ${ }^{22}$

Some researchers used $\mathrm{Fe}^{\mathrm{II}}$ and $\mathrm{Fe}^{0}$ to activate PS for the treatment of BPA, ${ }^{22,23}$ and some researchers studied sulfamonomethoxine, ciprofloxacin hydrochloride degradation in $\mathrm{Fe}_{3} \mathrm{O}_{4} / \mathrm{PS}$ systems. ${ }^{22,24,25}$ However, there are few studies towards BPA removal using $\mathrm{Fe}_{3} \mathrm{O}_{4} / \mathrm{PS}$ systems, especially the scavenging experiment of free radicals and the intermediate identification of BPA degradation products still need be further studied. In this paper, $\mathrm{Fe}_{3} \mathrm{O}_{4}$ magnetic particles have been used as activator to activate PS to produce free radicals for the removal of BPA. The performance of the $\mathrm{Fe}_{3} \mathrm{O}_{4} / \mathrm{PS}$ system on the degradation of BPA was systematically investigated, the possible effects of environmental factors on BPA removal, and BPA degradation mechanism were discussed in detail. Moreover, the role of active radical species was also explored using scavenging experiments, and the recycling performance of $\mathrm{Fe}_{3} \mathrm{O}_{4}$ was evaluated based on $\mathrm{Fe}_{3} \mathrm{O}_{4}$ reuse experiment.

\section{Experimental}

\section{Chemicals and equipment}

The main chemicals and equipment used in the experiments are present in Tables 1 and 2, respectively. The content of $\mathrm{Fe}_{3} \mathrm{O}_{4}$ in the iron oxide material is greater than $99.5 \%$, the particle size of iron oxide is $20 \mathrm{~nm}$, and the specific surface area of iron oxide is $51.46 \mathrm{~m}^{2} \mathrm{~g}^{-1}$.

\section{Batch experiments}

A $1000 \mathrm{mg} \mathrm{L}^{-1}$ of BPA aqueous stock solution was prepared for dilution into a series of concentrations in the batch experiments. The experiments were conducted in the $500-\mathrm{mL}$ beakers placed on a magnetic heating stirrer with

Table 1. The main experimental chemicals

\begin{tabular}{lccc}
\hline Chemical & Molecular formula & Purity & Supplier \\
\hline Bisphenol A & $\mathrm{C}_{15} \mathrm{H}_{16} \mathrm{O}_{2}$ & premium grade & McLean Co., Ltd. (Shanghai, China) \\
Iron oxide & $\mathrm{Fe}_{3} \mathrm{O}_{4}$ & analytical grade & McLean Co., Ltd. (Shanghai, China) \\
Sodium persulfate & $\mathrm{Na}_{2} \mathrm{~S}_{2} \mathrm{O}_{8}$ & analytical grade & Sinopharm Co., Ltd. (Shanghai, China) \\
Sodium hydroxide & $\mathrm{NaOH}$ & analytical grade & Tianjin Chemical Reagent Factory (Tianjin, China) \\
Sulfuric acid & $\mathrm{H}_{2} \mathrm{SO}_{4}$ & analytical grade & Beijing Chemical Reagent Factory (Beijing, China) \\
Methanol & $\mathrm{CH}_{3} \mathrm{OH}$ & chromatographically grade & Norsch Co., Ltd. (Chengdu, China) \\
tert-Butanol & $\mathrm{C}_{4} \mathrm{H}_{10} \mathrm{O}$ & chromatographically grade & McLean Co., Ltd. (Shanghai, China) \\
Hexane & $\mathrm{C}_{6} \mathrm{H}_{14}$ & analytical grade & Beijing Chemical Reagent Factory (Beijing, China) \\
Dichloromethane & $\mathrm{CH}_{2} \mathrm{Cl}_{2}$ & analytical grade & Beijing Chemical Reagent Factory (Beijing, China) \\
Sodium chloride & $\mathrm{NaCl}_{2}$ & analytical grade & Beijing Chemical Reagent Factory (Beijing, China) \\
Anhydrous sodium sulfate & $\mathrm{Na}_{2} \mathrm{SO}_{4}$ & analytical grade & Xilong Science Co., Ltd. (Shantou, China) \\
\hline
\end{tabular}


Table 2. The main equipment

\begin{tabular}{lcc}
\hline Equipment & Model & Manufacturer \\
\hline Ultra pure water machine & Elemental 1810 D & $\begin{array}{c}\text { Chongqing Moore Water Treatment Equipment Co., Ltd. } \\
\text { (Chongqing, China) }\end{array}$ \\
Electronic analytical balance & FA2104A & Shanghai Leigu Instrument Co., Ltd. (Shanghai, China) \\
Magnetic stirrer & SH-II-4C & Guangdong Foheng Instrument Co., Ltd. (Foshan, China) \\
pH meter & pHS-3C & Shanghai INESA Scientific Instrument Co., Ltd. (Shanghai, China) \\
High-phase liquid chromatography (HPLC) & G7121A & Agilent Technologies (China) Co., Ltd. (Shanghai, China) \\
Nitrogen blowing concentrator & XSF-12 & Shanghai Xuansheng Scientific Instrument Co., Ltd. (Shanghai, China) \\
Gas chromatography mass spectrometry (GC-MS) & 7890B-7000C & Agilent Technologies (China) Co., Ltd. (Shanghai, China) \\
Oven & GHG-9040N & Hangzhou Zhuochi Instrument Co., Ltd. (Hangzhou, China)
\end{tabular}

the operating speed of $200 \mathrm{rpm}$. Firstly, the BPA solution $(500 \mathrm{~mL})$ with the designed concentration was added to the beaker, then predetermined amount of PS and $\mathrm{Fe}_{3} \mathrm{O}_{4}$ was quickly plunge into the beaker to trigger the reaction. The reaction temperature was adjusted by the heater, and the $\mathrm{pH}$ was adjusted by adding $0.1 \mathrm{M} \mathrm{NaOH}$ or $\mathrm{H}_{2} \mathrm{SO}_{4}$ to the solution. The entire reaction time was set to $60 \mathrm{~min}$. Aliquots $(0.5 \mathrm{~mL})$ were taken out of the beaker and put into the sample bottle. Then, $0.5 \mathrm{~mL}$ ethanol was immediately added into the sample bottle to stop the reaction. The samples were taken every $10 \mathrm{~min}$ from the beaker, and the residual concentration of BPA of the final samples were detected by high-performance liquid chromatography (HPLC). For the scavenging of free radicals generated in the reaction, the experiments were performed by adding methanol $(\mathrm{MeOH})$ and tert-butanol (TBA) with preset concentrations in beakers.

\section{Analytical methods}

The BPA concentration in samples was examined by a HPLC equipped with a C18 column $(4.6 \mathrm{~mm} \times 150 \mathrm{~mm}$, $4 \mu \mathrm{m})$ by using a fluorescence detector at $228 \mathrm{~nm}$. The mobile phase was $70 \%$ methanol at a flow rate of $0.8 \mathrm{~mL} \mathrm{~min}^{-1}$. The excitation and emission wavelengths are 228 and $312 \mathrm{~nm}$, respectively. The temperature of the column compartment was $25^{\circ} \mathrm{C}$ and the injection volume was $20 \mu \mathrm{L}$. The retention time of BPA under above conditions was $3.48 \mathrm{~min}$.

The oxidation products of BPA were carried out by a gas chromatography-mass spectrometry (GC-MS). The chromatographic analysis was performed via injection in splitless mode (split ratio of 10:1, injection volume of $1 \mu \mathrm{L}$ ) at $260{ }^{\circ} \mathrm{C}$ using a quartz capillary column (length: $30 \mathrm{~m}$, inner diameter: $0.25 \mathrm{~mm}$, film thickness: $0.25 \mu \mathrm{m}$ ) with a helium flow of $1.0 \mathrm{~mL} \mathrm{~min}^{-1}$. The qualitative analysis was performed with electron ionization (EI) at $70 \mathrm{eV}$ using the full scan mode in the $m / z$ range of 45-280. The ion source and quadrupole temperature were maintained at 230 and $150{ }^{\circ} \mathrm{C}$, respectively.
The removal rate $\eta(\%)$ of BPA is calculated using equation 1, where $\mathrm{C}_{0}$ is the initial concentration of BPA $\left(\mathrm{mg} \mathrm{L}^{-1}\right), \mathrm{C}_{\mathrm{t}}$ is the BPA concentration after $\mathrm{t}$ min treatment $\left(\mathrm{mg} \mathrm{L}^{-1}\right)$. The fitting of the kinetic equations in the experiment are based on the first-order reaction kinetic equation, as shown in equation 2 , where $\mathrm{k}$ is the kinetic constant $\left(\mathrm{min}^{-1}\right), \mathrm{b}$ is the $\mathrm{y}$ intercept (no unit).

$$
\begin{aligned}
& \eta=\frac{\mathrm{C}_{0}-\mathrm{C}_{\mathrm{t}}}{\mathrm{C}_{0}} \times 100 \\
& \ln \left(\frac{\mathrm{C}_{\mathrm{t}}}{\mathrm{C}_{0}}\right)=-\mathrm{kt}+\mathrm{b}
\end{aligned}
$$

\section{Results and Discussion}

The effect of the initial $\mathrm{Fe}_{3} \mathrm{O}_{4}$ dose

As the activator of $\mathrm{PS}, \mathrm{Fe}_{3} \mathrm{O}_{4}$ plays a very important role in the reaction of $\mathrm{Fe}_{3} \mathrm{O}_{4} / \mathrm{PS}$ system. We investigated the effects of six $\mathrm{Fe}_{3} \mathrm{O}_{4}$ doses used in activating PS on removing BPA. The experimental results are presented in Figure 1. Without adding $\mathrm{Fe}_{3} \mathrm{O}_{4}$, the BPA removal rate can reach $19.68 \%$ by PS alone within $60 \mathrm{~min}$. We speculate that this was due to temperature or light energy, which promote PS to produce $\mathrm{SO}_{4}^{-{ }^{-}}$(equation 3), thereby removing BPA. A previous research ${ }^{26}$ confirmed that PS can be catalyzed by ambient temperature to form $\mathrm{SO}_{4}{ }^{--}$to degrade organic matter. As adding $\mathrm{Fe}_{3} \mathrm{O}_{4}$ to the system, the removal rate of $\mathrm{BPA}$ was significantly increased. The $\mathrm{Fe}^{\mathrm{II}}$ on the surface of $\mathrm{Fe}_{3} \mathrm{O}_{4}$ can react with PS to generate $\mathrm{SO}_{4}{ }^{--}$(equation 4), and the BPA was removed. As the dose of $\mathrm{Fe}_{3} \mathrm{O}_{4}$ increased from 0.1 to $0.2 \mathrm{~g} \mathrm{~L}^{-1}$, the BPA removal rate increased from 41.94 to $56.49 \%$ within $60 \mathrm{~min}$. When the dose of $\mathrm{Fe}_{3} \mathrm{O}_{4}$ was increased to $0.3-0.5 \mathrm{~g} \mathrm{~L}^{-1}$, the removal rate of BPA did not change much, compared with the BPA removal rate of $0.2 \mathrm{~g} \mathrm{~L}^{-1}$ of $\mathrm{Fe}_{3} \mathrm{O}_{4}$. We speculate that there are three possible reasons for this BPA degradation curve. Firstly, due to the increase of $\mathrm{Fe}_{3} \mathrm{O}_{4}$ dosage, more $\mathrm{Fe}^{\mathrm{II}}$ can be produced, and 
excessive $\mathrm{Fe}^{\mathrm{II}}$ will extinguish $\mathrm{SO}_{4}{ }^{--}$(equation 5), ${ }^{27}$ which will reduce the BPA removal rate. Secondly, the excessive $\mathrm{SO}_{4}{ }^{--}$formed can react between themselves and reduce the number of $\mathrm{SO}_{4}^{-{ }^{-}}$(equation 6). ${ }^{28}$ Finally, the increase in the amount of $\mathrm{Fe}_{3} \mathrm{O}_{4}\left(0.3-0.5 \mathrm{~g} \mathrm{~L}^{-1}\right)$ causes the consumption of PS to increase. At $40 \mathrm{~min}$, PS is exhausted and the number of free radicals decreases, so the degradation rate of BPA increases slowly.

$$
\begin{aligned}
& \mathrm{S}_{2} \mathrm{O}_{8}{ }^{2-} \stackrel{\text { energy }}{\longrightarrow} 2 \mathrm{SO}_{4}{ }^{--} \\
& \mathrm{Fe}^{\mathrm{II}}+\mathrm{S}_{2} \mathrm{O}_{8}{ }^{2-} \rightarrow \mathrm{Fe}^{\mathrm{III}}+\mathrm{SO}_{4}{ }^{--}+\mathrm{SO}_{4}{ }^{2-} \\
& \mathrm{Fe}^{\mathrm{II}}+\mathrm{SO}_{4}{ }^{--} \rightarrow \mathrm{Fe}^{\mathrm{III}}+\mathrm{SO}_{4}{ }^{2-} \\
& \mathrm{SO}_{4}{ }^{-}+\mathrm{SO}_{4}^{-{ }^{-}} \rightarrow \mathrm{S}_{2} \mathrm{O}_{8}{ }^{2-}
\end{aligned}
$$

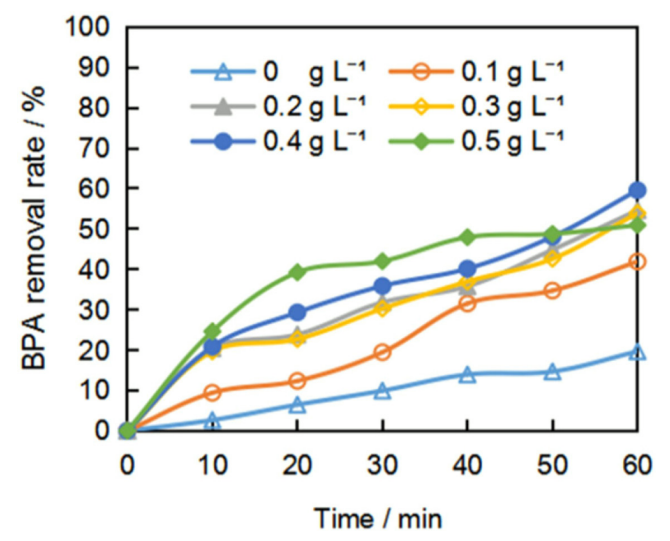

Figure 1. The effect of the initial $\mathrm{Fe}_{3} \mathrm{O}_{4}$ concentration on BPA removal. $[\mathrm{BPA}]_{0}=5 \mathrm{mg} \mathrm{L}^{-1},[\mathrm{PS}]_{0}=0.2 \mathrm{mM},\left[\mathrm{Fe}_{3} \mathrm{O}_{4}\right]_{0}=0-0.5 \mathrm{~g} \mathrm{~L}^{-1}, \mathrm{~T}_{0}=20 \pm 1^{\circ} \mathrm{C}$, $\mathrm{pH}_{0}=6.8 \pm 0.2$.

\section{The effect of the initial PS concentration}

The initial concentration of PS is an important factor affecting the BPA removal by $\mathrm{Fe}_{3} \mathrm{O}_{4}$ activation. Figure 2 gives the effect of the PS initial concentration on BPA degradation by $\mathrm{Fe}_{3} \mathrm{O}_{4}$ activation. In the absence of PS, it was found that $10.3 \%$ of BPA was removed within 60 min, indicating that $\mathrm{Fe}_{3} \mathrm{O}_{4}$ could adsorb BPA as an adsorbent. Sun et al. ${ }^{29}$ also found that nano- $\mathrm{Fe}_{3} \mathrm{O}_{4}$ can adsorb 2,4-dichlorophenol, but the efficiency was very low compared with $\mathrm{Fe}_{3} \mathrm{O}_{4} / \mathrm{PS}$ catalytic degradation. With the increase in the PS concentration from 0.1 to $0.3 \mathrm{mM}$, the BPA removal rate was elevated from 34.3 to $65.2 \%$ within $60 \mathrm{~min}$, which could be due to the larger amount of $\mathrm{SO}_{4}{ }^{--}$produced by $\mathrm{PS} / \mathrm{Fe}_{3} \mathrm{O}_{4}$ system (equation 4 ). However, when the initial concentration of PS increased from 0.3 to $0.5 \mathrm{mM}$, the BPA removal rate increased only by $1.4 \%$ within $60 \mathrm{~min}$. We have identified three possible reasons for this result. Firstly, excessive PS (0.4-0.5 mM) slowed down the degradation rate of BPA due to the elimination of $\mathrm{SO}_{4}{ }^{--}$by PS (equation 7). Secondly, more $\mathrm{SO}_{4}{ }^{--}$could also react with each other and lose their oxidation performance (equation 6). Finally, the increase in PS concentration causes the continuous consumption of $\mathrm{Fe}_{3} \mathrm{O}_{4}$, and the amount of $\mathrm{Fe}^{\mathrm{II}}$ released from $\mathrm{Fe}_{3} \mathrm{O}_{4}$ cannot meet the demand for high concentrations of PS. Therefore, the relatively insufficient amount of catalyst results in a slower reaction rate of catalyzing $\mathrm{PS}$ to $\mathrm{SO}_{4}{ }^{--}$, and ultimately affects the degradation efficiency of BPA.

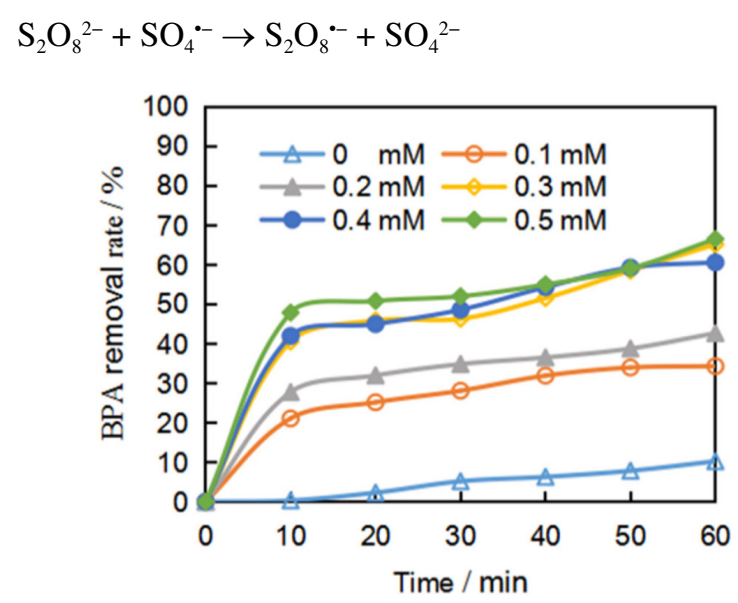

Figure 2. The effect of the initial PS concentration on BPA removal. $[\mathrm{BPA}]_{0}=5 \mathrm{mg} \mathrm{L}^{-1},[\mathrm{PS}]_{0}=0-0.5 \mathrm{mM},\left[\mathrm{Fe}_{3} \mathrm{O}_{4}\right]_{0}=0.1 \mathrm{~g} \mathrm{~L}^{-1}, \mathrm{~T}_{0}=20 \pm 1^{\circ} \mathrm{C}$, $\mathrm{pH}_{0}=6.8 \pm 0.2$.

\section{The effect of the initial BPA concentration}

The concentration of the substrate is also an important factor determining the degradation efficiency. It can be seen from the Figure 3 that when the initial BPA concentration increased from 1 to $5 \mathrm{mg} \mathrm{L}^{-1}$, after $60 \mathrm{~min}$ of reaction, the BPA removal rate dropped from 80.70 to $40.30 \%$. When the initial concentration of BPA is $5 \mathrm{mg} \mathrm{L}^{-1}$, the kinetic constant for BPA removal is $0.00942 \mathrm{~min}^{-1}$ $\left(\ln \left(C_{t} / C_{0}\right)=-0.00942 t+0.02804\right)$, and the reaction is the slowest. When the initial concentration of BPA was $1 \mathrm{mg} \mathrm{L}^{-1}$, the kinetic constant for BPA increased to $0.02466 \mathrm{~min}^{-1}\left(\ln \left(\mathrm{C}_{\mathrm{t}} / \mathrm{C}_{0}\right)=-0.02466 \mathrm{t}+0.09686\right)$, which was 2.6 times faster than the degradation rate of $5 \mathrm{mg} \mathrm{L}^{-1}$ BPA. As the amount of PS and $\mathrm{Fe}_{3} \mathrm{O}_{4}$ remained unchanged, the number of $\mathrm{SO}_{4}^{-}$- generated did not increase, and the increase of BPA concentration resulted to a relative shortage of $\mathrm{SO}_{4}^{--}$, which reduced the BPA removal rate. Therefore, in order to improve the degradation efficiency of BPA, the amount of oxidant and catalyst needs to be increased accordingly.

The effect of the initial $\mathrm{pH}$

It is clear that the advanced oxidation reaction in which PS is activated by transition metals is heavily 


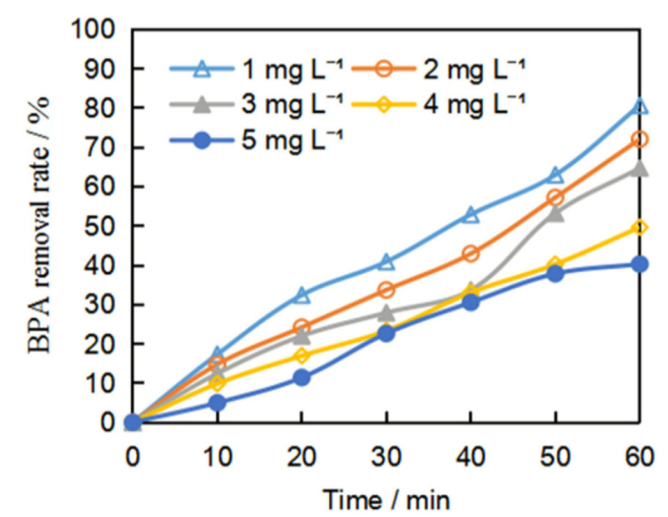

Figure 3. The effect of the initial BPA concentration on BPA removal. $[\mathrm{BPA}]_{0}=1-5 \mathrm{mg} \mathrm{L}^{-1},[\mathrm{PS}]_{0}=0.2 \mathrm{mM},\left[\mathrm{Fe}_{3} \mathrm{O}_{4}\right]_{0}=0.1 \mathrm{~g} \mathrm{~L}^{-1}, \mathrm{~T}_{0}=20 \pm 1^{\circ} \mathrm{C}$, $\mathrm{pH}_{0}=6.8 \pm 0.2$.

dependent on solution $\mathrm{pH}$. Therefore, we examined the BPA removal in $\mathrm{Fe}_{3} \mathrm{O}_{4} / \mathrm{PS}$ system at different $\mathrm{pH}$ of 3, 5, 7 and 9 (Figure 4). According to the BPA removal in descending order, the corresponding $\mathrm{pH}$ values were 5 , $3,7,9$, respectively. In other words, the $\mathrm{pH}$ value at the maximum BPA removal rate was 5 , with the removal rate of $59.2 \%$. Under acidic conditions of $\mathrm{pH} 3-5$, the reaction proceed more efficiently due to the solubilization of the $\mathrm{Fe}^{\mathrm{II}}$ on the surface of heterogeneous activator $\mathrm{Fe}_{3} \mathrm{O}_{4}$. Therefore, the homogeneous activation of $\mathrm{Fe}^{\mathrm{II}}$ occurs more effectively for generating $\mathrm{SO}_{4}{ }^{-}$towards removing BPA under acidic conditions. However, under neutral or alkaline conditions, $\mathrm{Fe}^{\mathrm{II}}$ can hydrolyze to produce the precipitant $\mathrm{Fe}(\mathrm{OH})_{2}$ which forms a passivation layer on the surface of $\mathrm{Fe}_{3} \mathrm{O}_{4}$, which hinders the migration of $\mathrm{Fe}^{\mathrm{II}}$ into water, and ultimately slows down the catalytic reaction. In addition, $\mathrm{SO}_{4}^{-{ }^{-}}$can react with $\mathrm{H}_{2} \mathrm{O}$ and $\mathrm{OH}$ to produce $\bullet \mathrm{OH}$ (equation 8) whose oxidizing power is less than $\mathrm{SO}_{4}^{-{ }^{-}}$. These reasons resulted in the reduction of BPA oxidation performance under alkaline conditions. This finding was similar to the study of

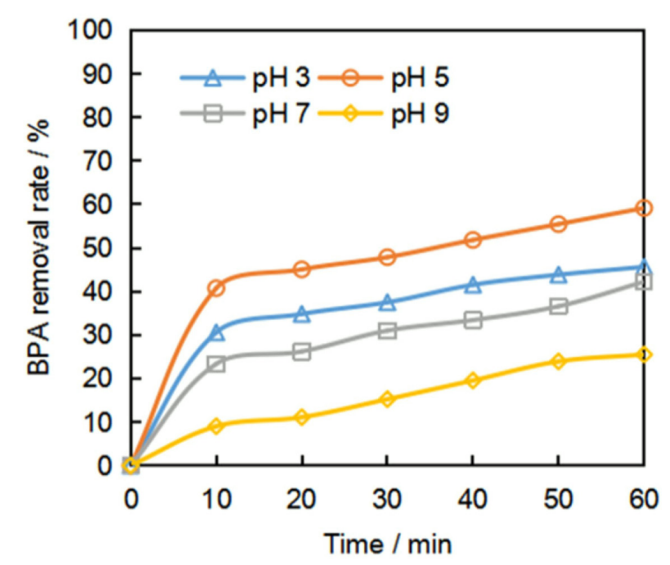

Figure 4. The effect of the initial $\mathrm{pH}$ concentration on BPA removal. $[\mathrm{BPA}]_{0}=5 \mathrm{mg} \mathrm{L}^{-1},[\mathrm{PS}]_{0}=0.2 \mathrm{mM},\left[\mathrm{Fe}_{3} \mathrm{O}_{4}\right]_{0}=0.1 \mathrm{~g} \mathrm{~L}^{-1}, \mathrm{~T}_{0}=20 \pm 1{ }^{\circ} \mathrm{C}$, $\mathrm{pH}_{0}=3-9$.
Liu et al..$^{30}$ about treatment of landfill leachate biochemical effluent using $\mathrm{Fe}_{3} \mathrm{O}_{4} / \mathrm{PS}$ system.

$\mathrm{OH}^{-}+\mathrm{SO}_{4}^{--} \rightarrow \cdot \mathrm{OH}+\mathrm{SO}_{4}{ }^{2-}$

The effect of the reaction temperature

Temperature is a crucial parameter in the treatment of wastewater as it can affect the rate of chemical reactions. Some scholars have reported experiments that high temperature can activate PS. ${ }^{31-33}$ We investigated the removal of BPA under four temperature conditions (20, 35, 50 and $70{ }^{\circ} \mathrm{C}$ ) in $\mathrm{Fe}_{3} \mathrm{O}_{4} / \mathrm{PS}$ and only PS system. The experimental results with or without $\mathrm{Fe}_{3} \mathrm{O}_{4}$ appearing in PS system at different temperatures are shown in Figure 5. In Figure 5, the curve marked with blank is the BPA removal without $\mathrm{Fe}_{3} \mathrm{O}_{4}$ (only PS). When only PS was added to the system, the removal rate of BPA increased significantly with the temperature increasing. The highest removal rate occurred at $70^{\circ} \mathrm{C}$ and the lowest removal rate occurred at $20^{\circ} \mathrm{C}$. When the temperature was $70{ }^{\circ} \mathrm{C}$, the fastest kinetic constant for BPA removal was $0.00821 \mathrm{~min}^{-1}\left(\ln \left(\mathrm{C}_{\mathrm{t}} / \mathrm{C}_{0}\right)=-0.00821 \mathrm{t}+0.01496\right)$, which was 2 times faster than the $20{ }^{\circ} \mathrm{C}$ rate of $0.00414 \mathrm{~min}^{-1}$ $\left(\ln \left(\mathrm{C}_{\mathrm{t}} / \mathrm{C}_{0}\right)=-0.00414 \mathrm{t}+0.00818\right)$. Since heat can activate $\mathrm{PS}$ to produce $\mathrm{SO}_{4}^{-{ }^{-}}$(equation 3 ), the increase in temperature was conducive to the degradation of BPA. When both PS and $\mathrm{Fe}_{3} \mathrm{O}_{4}$ were added to the system, the removal rate of BPA was significantly increased compared to the system with only PS. At 20 and $70{ }^{\circ} \mathrm{C}$, the removal rate of BPA was 40.46 and $87.10 \%$ after $60 \mathrm{~min}$, respectively. This showed high temperature and $\mathrm{Fe}_{3} \mathrm{O}_{4}$ have the ability to synergistically catalyze the degradation of BPA by PS. However, the higher the temperature, the more energy is consumed. The actual situation of sewage treatment

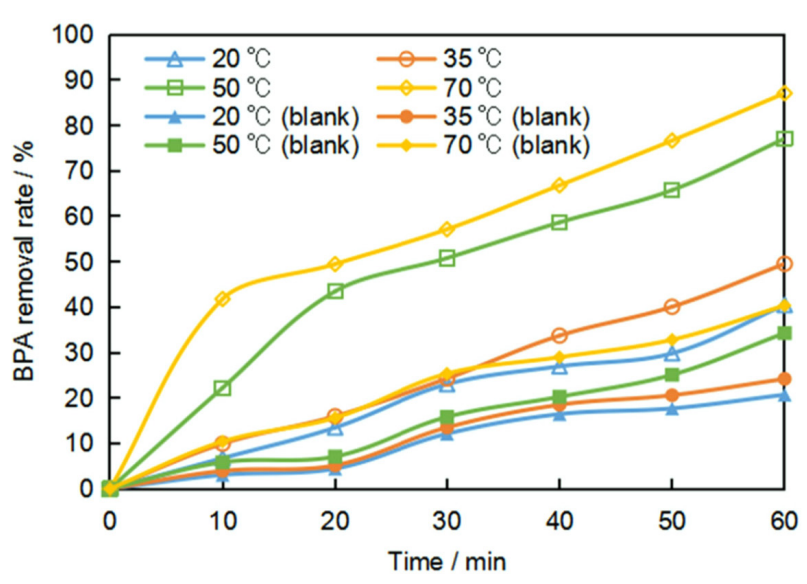

Figure 5. The effect of the reaction temperature on BPA removal. $[\mathrm{BPA}]_{0}=5 \mathrm{mg} \mathrm{L}^{-1},[\mathrm{PS}]_{0}=0.2 \mathrm{mM},\left[\mathrm{Fe}_{3} \mathrm{O}_{4}\right]_{0}=0 \mathrm{~g} \mathrm{~L}^{-1}, 0.1 \mathrm{~g} \mathrm{~L}^{-1}$, $\mathrm{T}_{0}=20-70{ }^{\circ} \mathrm{C}, \mathrm{pH}_{0}=6.8 \pm 0.2$. 
should be considered to determine the best temperature from the perspective of energy saving. In addition, as the temperature increased from 20 to $70^{\circ} \mathrm{C}$, only adding $\mathrm{Fe}_{3} \mathrm{O}_{4}$ to the system, the BPA removal rate increased from 10.22 to $12.18 \%$ (data not shown). In other words, as the temperature increased, $\mathrm{Fe}_{3} \mathrm{O}_{4}$ alone cannot improve the efficiency of its adsorption of BPA.

The scavenging of the free radicals

$\mathrm{MeOH}$ and TBA are commonly used chemical scavengers to distinguish $\mathrm{SO}_{4}{ }^{--}$and $\bullet \mathrm{OH}$ as they react with free radicals with different rate constants. $\mathrm{MeOH}$ is an effective scavenger for $\bullet \mathrm{OH}$ (reaction rate constant, $\left.\mathrm{k}=9.7 \times 10^{8} \mathrm{M}^{-1} \mathrm{~s}^{-1}\right)$ and $\mathrm{SO}_{4}^{-}{ }^{-}\left(\mathrm{k}=1.1 \times 10^{7} \mathrm{M}^{-1} \mathrm{~s}^{-1}\right)$, while TBA is an effective scavenger for $\bullet \mathrm{OH}\left(\mathrm{k}=6.0 \times 10^{8} \mathrm{M}^{-1} \mathrm{~s}^{-1}\right)$ and not for $\mathrm{SO}_{4}^{-{ }^{-}}\left(\mathrm{k}=9.1 \times 10^{5} \mathrm{M}^{-1} \mathrm{~s}^{-1}\right)$. As observed in Figure 6, without adding the $\mathrm{MeOH}$ or TBA, $48.5 \%$ of BPA degradation rate was acquired within $60 \mathrm{~min}$. The $\mathrm{MeOH}$ and TBA of $80 \mathrm{mM}$ added separately to the system resulted in BPA removal to drop to 25.9 and $45.4 \%$, respectively. As the concentration of $\mathrm{MeOH}$ and TBA increased to $800 \mathrm{mM}$, the degradation rate of BPA further decreased to 12.8 and $39.9 \%$. The addition of $\mathrm{MeOH}$ had a more obvious effect on the decrease of BPA degradation rate. Therefore, it was inferred that the $\mathrm{SO}_{4}^{-}{ }^{-}$generated in the reaction was the main free radical, followed by the $\bullet \mathrm{OH}$.

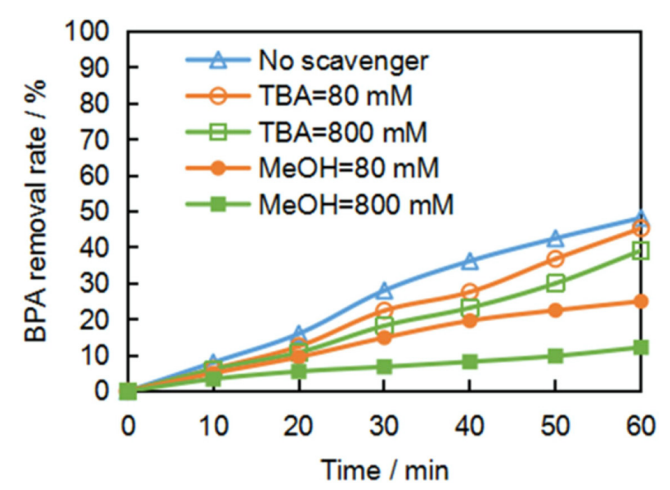

Figure 6. The effect of $\mathrm{MeOH}$ and TBA on BPA removal. $[\mathrm{BPA}]_{0}=5 \mathrm{mg} \mathrm{L}^{-1}$, $[\mathrm{PS}]_{0}=0.2 \mathrm{mM},\left[\mathrm{Fe}_{3} \mathrm{O}_{4}\right]_{0}=0.1 \mathrm{~g} \mathrm{~L}^{-1}, \mathrm{~T}_{0}=35 \pm 1^{\circ} \mathrm{C}, \mathrm{pH}_{0}=6.8 \pm 0.2$.

\section{BPA degradation products and pathways}

GC-MS was used to qualitatively analyze the intermediate product of BPA degradation by nano- $\mathrm{Fe}_{3} \mathrm{O}_{4}$ activated PS. The reaction conditions are as follows: $[\mathrm{BPA}]_{0}=5 \mathrm{mg} \mathrm{L}^{-1},[\mathrm{PS}]_{0}=0.2 \mathrm{mM},\left[\mathrm{Fe}_{3} \mathrm{O}_{4}\right]_{0}=0.4 \mathrm{~g} \mathrm{~L}^{-1}$, $\mathrm{T}_{0}=35 \pm 1{ }^{\circ} \mathrm{C}, \mathrm{pH}_{0}=5.0$. The possible intermediate products of BPA degradation are shown in Table 3. The detected intermediate products were mainly aromatic compounds, including phenol, $p$-benzoquinone, p-hydroquinone, 4-(2-hydroxypropan-2-yl) phenol, 4-isopropenylphenol, $p$-hydroxybenzene propanoic acid and 4-hydroxybenzoic acid. The possible degradation pathways of BPA are shown in Figure 7. The free radicals generated from nano- $\mathrm{Fe}_{3} \mathrm{O}_{4} / \mathrm{PS}$ system attacked the $\mathrm{C}-\mathrm{C}$ bond between isopropyl and benzene rings of bisphenol $\mathrm{A}$, forming 4-(2-hydroxypropan-2-yl)phenol and phenol. ${ }^{34}$ 4-(2-Hydroxypropan-2-yl) phenol was gradually oxidized into 4-isopropenylphenol, $p$-hydroxyphenylpropionic acid, and 4-hydroxybenzoic acid. ${ }^{35,36}$ Phenol was gradually oxidized into $p$-hydroquinone and $p$-benzoquinone. Then, all the aromatic compounds produced by two pathways were oxidized into small molecular compounds, ${ }^{17,37}$ some of which will be mineralized into $\mathrm{CO}_{2}$ and $\mathrm{H}_{2} \mathrm{O}$ under the conditions set in $\mathrm{Fe}_{3} \mathrm{O}_{4} / \mathrm{PS}$ system.

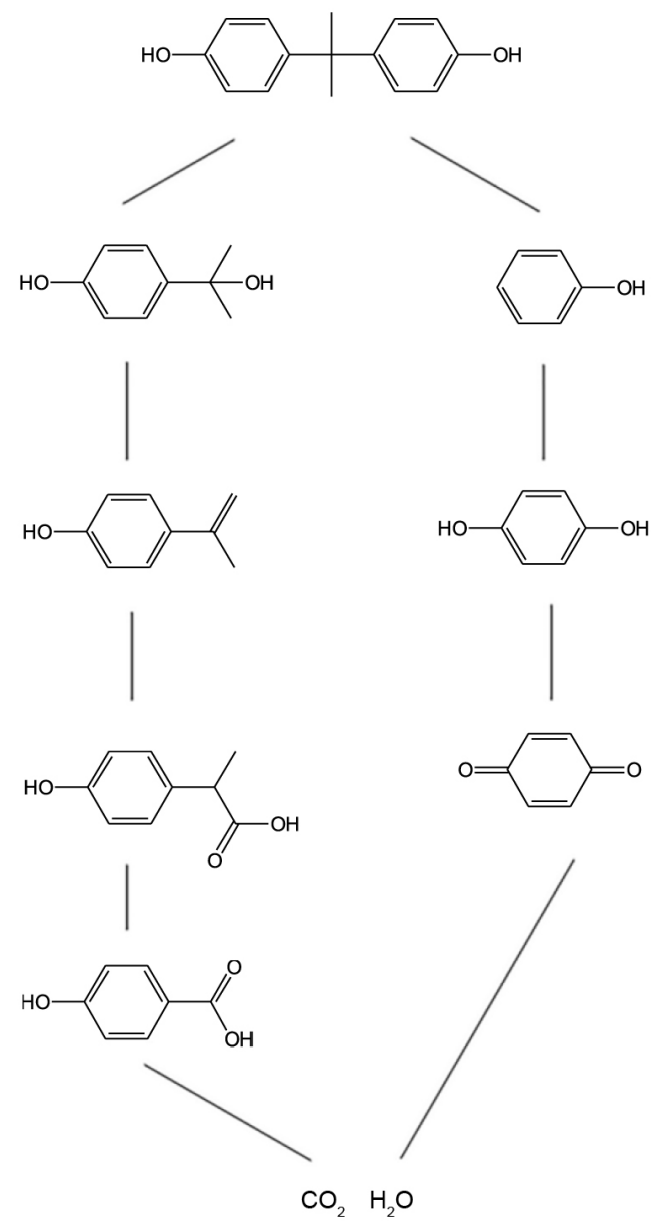

Figure 7. The possible degradation pathways of BPA.

Reusability of $\mathrm{Fe}_{3} \mathrm{O}_{4}$

In order to investigate the recyclability of $\mathrm{Fe}_{3} \mathrm{O}_{4}$, a magnet was used to separate $\mathrm{Fe}_{3} \mathrm{O}_{4}$ from the solution. After separation, the $\mathrm{Fe}_{3} \mathrm{O}_{4}$ was rinsed with deionized water, and dried indoors with natural ventilation for use in the next 
Table 3. The possible intermediates of BPA degradation

\begin{tabular}{|c|c|c|c|c|}
\hline Serial number & Chemical name & Molecular formula & $\begin{array}{l}\text { Molecular weight / } \\
\qquad\left(\mathrm{g} \mathrm{mol}^{-1}\right)\end{array}$ & Molecular structure \\
\hline 1 & bisphenol A & $\mathrm{C}_{15} \mathrm{H}_{16} \mathrm{O}_{2}$ & 228 & \\
\hline 2 & phenol & $\mathrm{C}_{6} \mathrm{H}_{6} \mathrm{O}$ & 94 & \\
\hline 3 & $p$-hydroquinone & $\mathrm{C}_{6} \mathrm{H}_{6} \mathrm{O}_{2}$ & 110 & \\
\hline 4 & $p$-benzoquinone & $\mathrm{C}_{6} \mathrm{H}_{4} \mathrm{O}_{2}$ & 108 & \\
\hline 5 & 4-(2-hydroxypropan-2-yl) phenol & $\mathrm{C}_{9} \mathrm{H}_{12} \mathrm{O}_{2}$ & 152 & \\
\hline 6 & 4-isopropenylphenol & $\mathrm{C}_{9} \mathrm{H}_{10} \mathrm{O}$ & 134 & \\
\hline 7 & $p$-hydroxybenzene propanoic acid & $\mathrm{C}_{9} \mathrm{H}_{10} \mathrm{O}_{3}$ & 166 & \\
\hline 8 & 4-hydroxybenzoic acid & $\mathrm{C}_{7} \mathrm{H}_{6} \mathrm{O}_{3}$ & 138 & \\
\hline
\end{tabular}

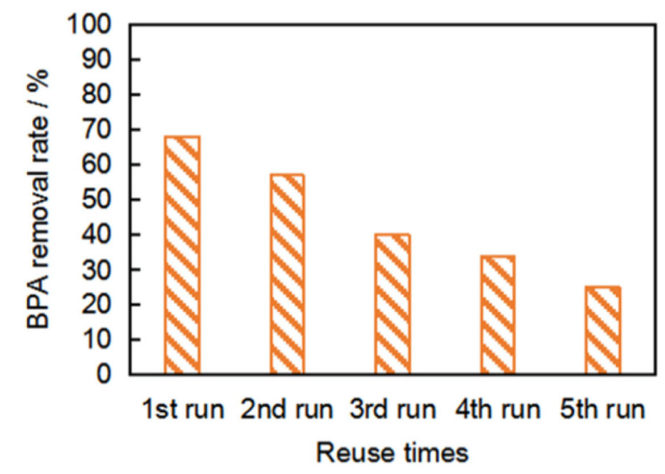

Figure 8. Reuse of $\mathrm{Fe}_{3} \mathrm{O}_{4}$ and $\mathrm{BPA}$ removal rate. $[\mathrm{BPA}]_{0}=5 \mathrm{mg} \mathrm{L}^{-1}$, $[\mathrm{PS}]_{0}=0.2 \mathrm{mM},\left[\mathrm{Fe}_{3} \mathrm{O}_{4}\right]_{0}=0.2 \mathrm{~g} \mathrm{~L}^{-1}, \mathrm{~T}_{0}=35 \pm 1^{\circ} \mathrm{C}, \mathrm{pH}_{0}=5 \pm 0.2$.

experiment. It can be seen from Figure 8 that the removal rate of BPA dropped from 68.0 to $26.9 \%$ after five cycles of $\mathrm{Fe}_{3} \mathrm{O}_{4}$. In the absence of $\mathrm{Fe}_{3} \mathrm{O}_{4}$, PS alone could remove about $20 \%$ of BPA, so it is believed that after five cycles of $\mathrm{Fe}_{3} \mathrm{O}_{4}$, the catalytic activity of $\mathrm{Fe}_{3} \mathrm{O}_{4}$ is already very low. It is speculated that the decrease in the activity of $\mathrm{Fe}_{3} \mathrm{O}_{4}$ is due to the fact that most of the $\mathrm{Fe}^{\mathrm{II}}$ becomes $\mathrm{Fe}^{\mathrm{III}}$ that cannot effectively activate PS. ${ }^{38}$

\section{Conclusions}

$\mathrm{Fe}_{3} \mathrm{O}_{4} / \mathrm{PS}$ performed well as a sulfate radical-based AOP process in degradation of endocrine disruptor BPA.
The removal rate of BPA was related to $\mathrm{Fe}_{3} \mathrm{O}_{4}$ dose, PS concentration, BPA concentration, $\mathrm{pH}$ and temperature. The best BPA removal rate of $80.7 \%$ could be acquired under the selected conditions of $[\mathrm{BPA}]_{0}=1 \mathrm{mg} \mathrm{L}^{-1},[\mathrm{PS}]_{0}=0.2 \mathrm{mM}$, $\left[\mathrm{Fe}_{3} \mathrm{O}_{4}\right]_{0}=0.1 \mathrm{~g} \mathrm{~L}^{-1}, \mathrm{~T}_{0}=20 \pm 1^{\circ} \mathrm{C}, \mathrm{pH}_{0}=6.8 \pm 0.2$. The oxidation of BPA by $\mathrm{Fe}_{3} \mathrm{O}_{4} / \mathrm{PS}$ mainly relies on sulfate radicals generated during the reaction, and hydroxyl radicals play a minor role. The possible intermediates of BPA degradation were determined as phenol, $p$-benzoquinone, p-hydroquinone, 4-(2-hydroxypropan-2-yl) phenol, 4-isopropenylphenol, $p$-hydroxybenzene propanoic acid and 4-hydroxybenzoic acid. The performance of $\mathrm{Fe}_{3} \mathrm{O}_{4}$ was significantly reduced after five times of reuse.

\section{Acknowledgments}

The authors wish to acknowledge the financial support from the National Natural Science Foundation of China (grants No. 42077160) and Jilin Province Education Department of China (grants No. JJKH20200288KJ).

\section{References}

1. Vandenberg, L. N.; Hauser, R.; Marcus, M.; Olea, N.; Welshons, W. V.; Reprod. Toxicol. 2007, 24, 139.

2. Pahigian, J. M.; Zuo, Y.; Chemosphere 2018, 207, 469. 
3. Li, C.; Wang, Z.; Yang, Y. J.; Liu, J.; Mao, X.; Zhang, Y.; Chemosphere 2015, 125, 86.

4. Andaluri, G.; Manickavachagam, M.; Suri, R.; Environ. Monit. Assess. 2018, 190, 65.

5. Huang, Y. Q.; Wong, C. K. C.; Zheng, J. S.; Bouwman, H.; Barra, R.; Wahlstrom, B.; Neretin, L.; Wong, M. H.; Environ. Int. 2012, 42, 91.

6. Arslan-Alaton, I.; Olmez-Hanci, T.; Dogan, M.; Ozturk, T.; Water Sci. Technol. 2017, 76, 2455.

7. Rykowska, I.; Wasiak, W.; Acta Chromatogr. 2006, 16, 7.

8. Wirasnita, R.; Hadibarata, T.; Yusoff, A. R. M.; Yusop, Z.; Water, Air, Soil Pollut. 2014, 225, 2148.

9. Sharma, V. K.; Anquandah, G. A.; Yngard, R. A.; Kim, H.; Fekete, J.; Bouzek, K.; Ray, A. K.; Golovko, D.; J. Environ. Sci. Health, Part A: Toxic/Hazard. Subst. Environ. Eng. 2009, 44, 423.

10. Careghini, A.; Mastorgio, A. F.; Saponaro, S.; Sezenna, E.; Environ. Sci. Pollut. 2015, 22, 5711.

11. Akbari, S.; Ghanbari, F.; Moradi, M.; Chem. Eng. J. 2019, 294, 298.

12. Dong, Y.; Wu, D.; Chen, X.; Lin, Y.; J. Colloid Interface Sci. 2010, 348, 585.

13. Sui, Q.; Huang, J.; Liu, Y.; Chang, X.; Ji, G.; Deng, S.; Xie, T.; Yu, G.; J. Environ. Sci. 2011, 23, 177.

14. Bourgin, M.; Bichon, E.; Antignac, J. P.; Monteau, F.; Leroy, G.; Barritaud, L.; Chachignon, M.; Ingrand, V.; Roche, P.; le Bizec, B.; Chemosphere 2013, 93, 2814.

15. Choi, K. J.; Kim, S. G.; Kim, C. W.; Park, J. K.; Korean J. Chem. Eng. 2006, 23, 399.

16. Dupuis, A.; Migeot, V.; Cariot, A.; Albouy-Llaty, M.; Legube, B.; Rabouan, S.; Environ. Sci. Pollut. Res. Int. 2012, 19, 4193.

17. Sharma, J.; Mishra, I. M.; Kumar, V.; J. Environ. Manage. 2016, 166, 12.

18. Umar, M.; Roddick, F.; Fan, L.; Aziz, H. A.; Chemosphere 2013, 90, 2197.

19. Yang, D.; Zhou, X.; Liang, J.; Xu, Q.; Wang, H.; Yang, K.; Wang, B.; Wang, W.; J. Phys. D: Appl. Phys. 2021, 54, 244002.

20. Hong, Q.; Liu, C.; Wang, Z.; Li, R.; Liang, X.; Wang, Y.; Zhang, Y.; Song, Z.; Xiao, Z.; Cui, T.; Heng, B.; Xu, B.; Qi, F.; Ikhlaq, A.; Chem. Eng. J. 2021, 417, 129238.
21. Moreira, F. C.; Rui, A.; Brillas, E.; Vilar, V. J. P.; Appl. Catal., B. 2015, 162, 34 .

22. Jiang, S.; Zhu, J.; Wang, Z.; Ge, M.; Zhu, H.; Jiang, R.; Zong, E.; Guan, Y.; Ozone: Sci. Eng. 2018, 40, 457.

23. Gao, F.; Li, Y.; Xiang, B.; Ecotoxicol. Environ. Saf. 2018, 158, 239.

24. Sepyani, F.; Soltani, R.; Jorfi, S.; Godini, H.; Safari, M.; J. Environ. Manage. 2018, 224, 315.

25. Hu, Y.; Zhu, Q.; Yan, X.; Liao, C.; Jiang, G.; Environ. Res. 2019 , $178,108732$.

26. Liang, C.; Wang, Z. S.; Bruell, C. J.; Chemosphere 2007, 66, 106.

27. Yan, J.; Lei, M.; Zhu, L.; Anjum, M. N.; Zou, J.; Tang, H.; J. Hazard. Mater. 2011, 186, 1398.

28. Ouyang, D.; Yan, J.; Qian, L.; Chen, Y.; Han, L.; Su, A.; Zhang, W.; Ni, H.; Chen, M.; Chemosphere 2017, 184, 609.

29. Sun, C.; Zhou, R.; E, J.; Sun, J.; Su, Y.; Ren, H.; RSC Adv. 2016, $6,10633$.

30. Liu, Z.; Li, X.; Rao, Z.; Hu, F.; J. Environ. Manage. 2018, 208 , 159.

31. Yang, S.; Wang, P.; Yang, X.; Shan, L.; Zhang, W.; Shao, X.; Niu, R.; J. Hazard. Mater. 2010, 179, 552.

32. Potakis, N.; Frontistis, Z.; Antonopoulou, M.; Konstantinou, I.; Mantzavinos, D.; J. Environ. Manage. 2017, 195, 125.

33. He, L.; Chen, H.; Wu, L.; Zhang, Z.; Ma, Y.; Zhu, J.; Liu, J.; Yan, X.; Li, H.; Yang, L.; Ecotoxicol. Environ. Saf. 2021, 208, 111522 .

34. Du, J.; Bao, J.; Liu, Y.; Ling, H.; Zheng, H.; Kim, S. H.; Dionysiou, D. D.; J. Hazard. Mater. 2016, 320, 150.

35. Torres-Palma, R. A.; Nieto, J. I.; Combet, E.; Pétrier, C.; Pulgarin, C.; Water Res. 2010, 44, 2245.

36. Dong, Z.; Zhang, Q.; Chen, B. Y.; Hong, J.; Chem. Eng. J. 2019 , $357,337$.

37. Li, X.; Wang, Z.; Zhang, B.; Rykov, A. I.; Ahmed, M. A.; Wang, J.; Appl. Catal., B 2016, 181, 788.

38. Leng, Y.; Guo, W.; Shi, X.; Li, Y.; Wang, A.; Hao, F.; Xing, L.; Chem. Eng. J. 2014, 240, 338.

Submitted: May 5, 2021

Published online: August 19, 2021 